\title{
Impose with Leeway: Combining an Engineering and Learning Approach in the Management of Public-Private Collaboration
}

\author{
Nitesh Bharosa, Haiko van der Voort, Joris Hulstijn, Marijn Janssen, \\ Niels de Winne, and Remco van Wijk \\ Delft University of Technology, Jaffalaan 5, 2628 BX Delft, The Netherlands \\ \{n.bharosa, h.g.vandervoort, j.hulstijn,m.f.w.h.a.janssen, \\ r.vanwijk;n. dewinne\} atudelft.nl
}

\begin{abstract}
The ongoing financial crisis is forcing governments to consider leaner (less resource intensive) forms of public service delivery. This is a difficult process, especially since recent private sector scandals demand that governments become more vigilant. Public-private collaboration (PPC) needs to address this 'lean yet vigilant' challenge. However, PPCs have proven to take a long time to establish and bring to fruition. Hurdles that delay the achievement of goals include the need to agree on standards in an environment with heterogeneous interests, changing laws and unclear revenue models. While literature on managing PPC hints towards the need for both compulsory measures (plan-driven, restrictive) and adaptive measures (learning-driven, leeway), case studies illustrating how these measures can be integrated in practice are scarce. Drawing on the Standard Business Reporting case in the Netherlands, this paper shows that both compulsory and adaptive measures are necessary to advance in multi-actor standardization processes. Our findings indicate that PPC managers need to impose with leeway by taking an engineering approach to architecture development yet providing leeway in the details.
\end{abstract}

Keywords: Public-private collaboration, engineering, policy making, standard business reporting.

\section{Introduction}

Following the global financial crisis, governments around the world face a thorny dilemma. On the one hand, they need to cut cost and become leaner. One way to achieve this goal is to reduce their compliance monitoring tasks and request fewer business reports from the private sector. On the other hand, private sector failures and scandals in various domains (e.g., financial reporting, food, oil) demand that government agencies become more vigilant. More vigilance is often associated with more regulations, more business reporting and information provision to various government agencies. In addition, more vigilance (e.g., regular inspections) often increases the compliance-monitoring burden for government agencies. This dilemma does not necessarily require government agencies to perform more tasks with fewer 
(human) resources. For instance, when it comes to regulation and monitoring tasks, government agencies can perform their tasks more efficiently depending on the agreements with the sector monitored. When developing architectures for publicprivate information exchange, a key step in addressing this dilemma is to collaborate with the public sector [1]. In order to come to such agreements, various forms of public-private collaboration (PPC) are discussed in literature [2]. Tan et al., [3] for instance report on a form of PPC in supply chains driven by the need to conduct more efficient and effective compliance monitoring. In such forms of PPC, trust and coordination are important drivers for collaboration. Kerschbaumer [4] reports on the rise of PPC in the health sector, primarily driven by the need standardize information flows, share resources and risks. In general, PPC is characterized by common objectives, as well as risks and rewards, as might be defined in a contract or manifested through a different arrangement, so as to effectively deliver a service or facility to the public [5]. The private sector partner may be responsible for all or some project operations, and financing can come from either the public or private sector partner or both.

In practice, several key types of PPCs can be found across various public sectors. Collaborating with the private sector carries the potential for meaningful benefits to be gained for the public partner and, in some cases the citizen. As such, PPCs are key in achieving a lean government, with reduced spending (e.g., eliminating large upfront investments of scarce public funds), greater efficiency (e.g., due to private partners' operational efficiency), and better management (e.g., of public services and infrastructure). In sectors which traditionally are subject to much regulation and compliance monitoring by government agencies, PPC can also be particularly valuable as a method of leveraging technical or management expertise (e.g., performance-based monitoring and incentives), and spurring technology transfer, all of which can lead to quality improvements. Nevertheless, studies show that managing the transition from traditional government regulation to PPC has proven to be difficult in practice [6]. Many PPCs crucially depend on information systems. Such systems need to be developed along with the collaboration. Information systems supporting PPCs involve complex inter-dependencies between processes, data and technology infrastructures. In many cases, the interest of the public and private stakeholders are divergent and sometimes even conflicting [5]. For instance, the interests of the public sector are related to legislation, regulations and authorities, political opinion and political influence, democratic decision-making processes, the minimization of risks and the realization of a social goal. One the other hand, the interests of the private sector, are related to revenues on the invested funds, daring to take business risks, having to anticipate market and competitive developments; realizing a corporate goal.

Top-down management approaches are hardly effective in these situations [7], mainly because they fail in facilitating the level of flexibility needed to deal with the wide range of varying stakeholder needs and project uncertainties. A more open approach, providing room to maneuver for stakeholders seems to be more appropriate. While contemporary literature on project management [e.g., 8] hints towards the integration of plan driven and adaptive learning measures, empirical contributions on how these measures were combined in practice and what kind of effects they had is scarce. This scarcity can be partly attributed to the fact that PPCs emerge in a relatively unstructured manner, often depending on the political agenda, making it 
difficult to collect data. This paper elaborates on the integration of compulsory and adaptive measures that have proven to facilitate the steady advancement of a PPC program in the Netherlands. The case study is on Standard Business Reporting (SBR), a PPC based lean-government initiative aiming to reduce that regulation burden for companies, while at the same time reducing the compliance-monitoring burden for government agencies such as the tax-office and Chamber of Commerce. Section 3 presents more detail on the SBR case. Since SBR is a new form of PPC consisting of several projects, stakeholders needed a program management methodology that addresses the various complexities and uncertainties inherent to the standardization of data, processes and infrastructure for business-to-government information exchange. Note that we do not claim to have developed a new program management approach. Instead, the objective of this paper is to highlight the combination of compulsory and adaptive measures that were used in managing a PPC in practice. As part of the case study, we collected data through observation, document analysis and interviews with members of the SBR team in the Netherlands.

This paper proceeds as follows. Section 2 illuminates some of the typical uncertainties and progress inhibitors in PPC management found in literature. Section 3 presents some background on the introduction of SBR in the Netherlands. Section 4 discusses the findings and reflects on the combination of measures used in the SBR case study. This paper concludes with some avenues for further research.

\section{Public-Private Collaboration Management: Marrying Two Extreme Management Styles}

A well-known governance tool for complex projects is project management [9]. Typical of project management thinking is getting things done in a limited time frame with predefined quality standards and costs [7]. The main problem for a project manager is framed as controlling just these aspects: time, costs and quality. Project management is an example of an 'engineering approach' to management. An analyst (or an engineer) designs a system that is supposed to be optimal, which makes management an implementation issue. A well-known other example of such an engineering approach is Business Process Re-engineering (BPR) [10].

The growth of the use of project management as a form of governance is supported by a growing set of tools, aimed at predicting the design through system engineering, the tasks through a work-breakdown structure, the time to spend through network planning tools and the budget through various cost-estimation techniques [9, 11]. Project management adds instruments to ensure that the predicted outcome is actually the real outcome of the project. Project managers are responsible for fulfilling the strictly predefined tasks, which implies a top-down steering approach. Organizational change management, risk management and progress management are tools to command, control and secure that the prediction is realistic and realised. More and more, however, these project management tools are deemed inappropriate for the complexities and dynamics that come from multi-stakeholder networks. An important source of complexity is the need to invent context specific solutions by combining technologies, knowledge, and expertise - dispersed over various actors [12]. Consequently, these projects behave less predictably and as such, the predictions are 
less accurate, and control focusing on realising that prediction is less apt. The alternative then is to shift towards adaptive forms of management that focus more on flexibility, cooperation, learning and trust. The underlying bodies of knowledge originate from outside de engineering world, such as public administration, institutional economy and sociology. These draw on literature on innovation, network governance, complexity and innovation, suggesting approaches such as adaptive planning [13], concurrent engineering [14] and process management [7, 15]. They underline the need for "bonding for internal cohesion" and flexibility. The idea is that surprises will inevitably occur in complex projects. In those situations, the project manager does not need team members, partners and contractors with neatly and narrowly described tasks but broad-thinking and committed collaborators with room to manoeuvre. The manager needs to prepare for surprises and commit everyone involved to dealing with them. Part of that preparation can be to use a broader, more functional description of requirements [16]. Along the way, lessons will be learnt by the client about what it wants and by other actors (e.g., regulators, accountancy firms, software providers, intermediaries) about what is possible and efficient. Learning requires bottom-up steering processes, room in terms of resources, time and budget, allowing for experimenting, the making, detecting and correcting of mistakes, and the exchanging of experiences. Working in a constantly learning and flexible environment demands suitable contracts that focus on realising a prescribed function rather than a prescribed system. Therefore, incentives and performance measurement are more output-based than work-task based. Furthermore, the project management requires leeway; administrators, politicians and stakeholders allowing it discretionary freedom.

Table 1. Two extreme management approaches

\begin{tabular}{|l|l|l|}
\hline Assumptions & $\begin{array}{l}\text { An engineering approach } \\
\text { Systems are fully specifiable, } \\
\text { predictable, and can be built } \\
\text { through extensive planning }\end{array}$ & $\begin{array}{l}\text { A learning approach } \\
\text { bystem components can be developed } \\
\text { continuous design improvement and } \\
\text { testing based on rapid feedback and } \\
\text { change }\end{array}$ \\
\hline Management style & Command and control & Cooperation \\
\hline Requirements & Blueprint & Functional \\
\hline Task definition & Narrow for best control & Broad for best cooperation \\
\hline Incentives & Work-task based & System-output based \\
\hline Change & Limit as much as possible & Facilitate as much as needed \\
\hline Steering & Top down & Bottom up \\
\hline $\begin{array}{l}\text { Information } \\
\text { exchange }\end{array}$ & Limited & Open \\
\hline
\end{tabular}

The two approaches outlined in Table 1 are extreme representations of possible managerial approaches. It is doubtful whether such a pure form would be effective at all in any kind of project. The engineering approach - as drawn here - does not suit the complexities and dynamics of multi-actor system behavior. The adaptive approach is too open-ended to function in any environment that poses constraints, such as political environments imposing deadlines. A growing stream of literature on project 
management and innovation suggests that an effective managerial is likely to meet the best of both worlds. It is meandering between the two extremes [17]. It is being strict about some aspects and lenient about others. De Bruijn and Ten Heuvelhof [5] have developed idea about how to combine both extremes. They suggest command and control by leeway. An engineering approach provides direction and incentives to actors to behave in an orchestrated manner. It, however, becomes vulnerable if main interests of actors are not addressed in the managerial approach. Resistance is problematic when the cooperation of actors is essential for the program or project. A different vulnerability is the fact that essential knowledge is dispersed over the actors involved and evolving over time. Providing room to actors may mitigate their resistance and provides an opportunity to distribute and use their knowledge. An example of combining command and control with providing room is output-based management: time, costs and/or quality standards are well defined and enforced strictly, but the way to meet these standards are open for discussion or decentralized decision-making.

This idea provides us a broadly defined normative framework for public management of compliance processes. It calls for some balance between two extreme management approaches, an intelligent mix profiting from the virtues of both. A balance might be found in using an engineering approach and the same time provide room to maneuver for the actors involved. However, this is still not a full-grown framework. Many 'how'- questions remain. Literature does not address complexities of specific PPC projects. Case studies are needed to show the validity of the framework and refine it. The next section presents a case study on the development of an architecture for standard business reporting in the Netherlands.

\section{Case Study: Introducing Standard Business Reporting in the Netherlands}

This section contains an illustration of the compulsory and adaptive techniques and practices used in the implementation of Standard Business Reporting (SBR) in the Netherlands. SBR concerns the implementation of the set of agreements and information systems used for the exchange of reporting information between companies and pubic organizations. SBR implementation combines both restrictive and adaptive measures such as the ones discussed earlier. The management approach that has been used in the SBR program has two partitioning principles. Firstly, development proceeds iteratively in phases with clear deadlines and deliverables: analysis and design, implementation, execution and monitoring. This provides a temporal partitioning. Secondly, there is a separation between the different layers of a projected solution: process layer, data layer, technological infrastructure, and governance aspects.

\subsection{Background}

In the Netherlands, the Standard Business Reporting Program (SBR Program) is a set of projects in the area of business to government information exchange. In the SBR Program, several government agencies and industry partners collaborate to simplify 
and standardize (financial) reporting [18]. This collaboration is encapsulated in an agreement (covenant) that was signed by over eighty parties, both public and private.

The program started in 2004 as Netherlands Taxonomy Project (NTP). In 2006, a generic infrastructure project was carried out drawing up requirements for a new process infrastructure for financial reporting based on the Extensible Business Reporting Language (XBRL). XBRL is an XML based computer language for reporting business information enabling data to be tagged and reused [19]. In 2007, the first versions of the technical infrastructure developed for exchanging the data were ready. Stakeholders decided that the government should maintain the infrastructure IT maintenance agency Logius. In 2009, the taxonomy project was handed over to Logius altogether and a steering group consisting of senior representatives of all Ministries involved was appointed. As of 2009, NTP continues under the international name Standard Business Reporting (SBR). Similar approaches have been adopted by Australia, and later also New Zealand, China and Singapore.

Reporting streams in SBR include company (or its intermediary) to the CBS (production statistics, investment statistics and short-term statistics, i.e. revenue per period), Chambers of Commerce (possibility to file the annual financial report) and Tax Office (revenue taxes, corporate taxes, income taxes, intra-EU performance (ICP), and short versions of corporate and income taxes. The business information supply chain starts with companies possibly reporting via an intermediary (accountant, bookkeeping, tax consultant etc.), who are both supported by software providers. In the middle, we find the various taxonomy variants chosen for the different reporting streams, and the gateways. Institutions demanding reports are shown on the right. Information flows follow a 'store once, report to many' principle. According to this principle, the data definitions and the infrastructure may be re-used over different reporting chains, while the actual act of reporting remains specifically addressed to one agency. Based on current legislation, the one-stop-shop scenario [20] or the single window based continuous monitoring scenario [3] would be too far reaching for three reasons. Firstly, it is legally not allowed to re-use data collected for one purpose, for different purposes. Secondly, because reports may have different legal functions and they have different contents. Thirdly, because data for different report may have a different quality level, aggregation level, precision or source.

\subsection{Development Phases}

In the SBR case, a development schedule with pre-defined development phases is enforced quite strictly. Figure 2 shows a development schedule as it has been used in several rollout projects in the SBR domain. There are two go/no go decision making moments. The first one is after the analysis and design phase, when commitment is needed that the project will go ahead as specified in the blueprint. Note that analysis and design are merged. This does not mean that a requirements specification (analysis) and a design (blueprint) should not be separate deliverables, but rather that determining requirements and developing ideas about what is feasible should be intertwined. Another reason is that these phases involve similarly skilled people: visionaries and architects, with an eye for unforeseen possibilities. By contrast, the implementation phase needs project managers who get the job done. In the third phase, the implemented process and technology components are deployed in practice. 


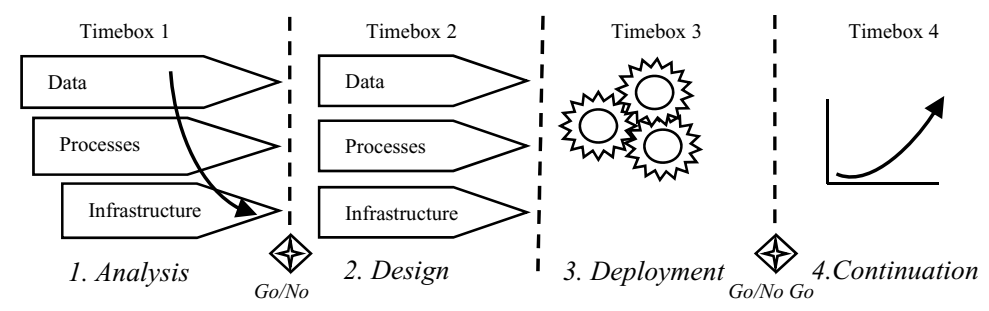

Fig. 1. SBR implementation approach

Initially this is done in a smaller application area. Only after evaluation and acceptance of the working solution, and with an enriched business case, a roadmap can be drawn up to scale up deployment in other application areas. This also involves a marketing plan to make sure external parties (e.g., companies, intermediaries) will adopt the new way of reporting.

Figure 1 outlines the main phases in the deployment of SBR in the Netherlands. Stakeholders have recognized that the implementation of SBR will be a cyclical program, consisting of four recurring activities: analysis, design, deployment and continuation. There are two go/no-go moments built into this cycle, during which stakeholders decide on the progression to the next phase depending on the quality of the deliverables. The following sections discuss the combination of compulsory and adaptive measures regarding the data, processes, infrastructure and governance in the SBR case.

\subsection{Process Layer}

One of the major dilemmas for compliance management was gaining agreement on process definitions across the chain of stakeholders. To model reporting processes Business Process Modeling Notation (BPMN) was proposed as standard. As an recognized standard for business process modeling [21], BPMN makes it possible for everyone involved in the reporting process a clear picture and description of the process steps that are in a reporting chain. Accordingly, BPMN modeling provides the basis for implementing the process steps. While the use of BPMN is compulsory, compliance managers soon found out that these standards were not sufficient to capture the complexity and context specificity of the entire reporting process. As such, the use of additional process definitions (e.g., in text) was allowed. When we consider the process of reporting, an interesting dilemma was choosing the type of gateway for facilitating the reporting streams. At first, a one stop shop [20] was envisioned, referring to a single point of access from a customer of public administration's point of view. This type of infrastructure requires a high level of integration and standardization across the information systems of the requesting agencies. Moreover, the one-stop-shop infrastructure would be too far reaching. First, current legislation does not permit the re-use of data collected for one purpose to be used for a different purpose. Secondly, because reports may have a different function and may therefore have different contents. For example, in a tax report, the company 
will try to report as little revenue as possible. In a year-end financial statement meant for shareholders, a company will try to report as much revenue as possible, to appear as a solid investment opportunity. As an intermediate solutions, the program managers opted for a 'store once, report to many'-infrastructure. This means that although the data definitions and the infrastructure may be re-used over different reporting chains, the actual act of reporting remains specifically addressed to one agency. Hence, the gateway will operate much like a post office, simply moving electronic messages from businesses' system to the right agency, and returning an electronic receipt. This provides leeway for the requesting agencies in organizing their internal processes.

\subsection{Data Layer}

Concerning the data layer, we discuss the dilemma of allowing extensions, versus uniformity of a standard (Section 3.4). As was explained above, the general policy in the SBR program is to prefer the national XBRL taxonomy, but to also allow other open standard data formats for specific domains (alternatives of XML, for instance for human resource management). In the case of the banks, an intermediate solution is chosen. Banks use their own extension of the taxonomy, but in the release schedule they follow updates of the national XBRL taxonomy. Therefore, users can still expect to re-use the common data part. Another issue concerns the possibility of XBRL to generate different reports from the same data, by using presentation formats. This leads to a legal problem. By law, an accountant verifies whether the annual accounts present a 'fair image' of commercial reality. When the metaphor of an image is taken too literally, this means that the accountant can only sign for the actual presentation chosen; not for the underlying data elements. After all, not only accuracy but also completeness is testified. This issue still needs to be settled by experts of the Dutch accountants association.

\subsection{Technical Infrastructure Layer}

In the SBR program, Digipoort functions as the main gateway for information exchange between the private sector and government agencies. SBR uses open technology standards were possible. As compulsory measure, companies have to connect to Digipoort (using free coupling specifications) which is the exclusive gateway for system-to-system reporting in XBRL. Leeway is provided in the way companies (or their intermediaries) connect their business data systems to Digipoort. Companies are free in deciding which of their systems (e.g., financial, accounting, ERP) they connect to Digipoort and to what extend XBRL is embedded in their business transactions (i.e., bolt on, build in or embedded).

\subsection{Governance}

A strict release schedule is maintained for different stakeholders. In this way, partners can test and use the taxonomy - so possible defects are - found before troubling market parties. As we mentioned, according to the Weill and Ross model we need to determine three things. First, SBR is governed by a council, in which all major stakeholders have a say. User groups are represented in the SBR platform. They can 
give feedback on the way the program develops. The platform is supported by three expert groups, one for data, one for processes and technology and one for marketing and communications. Expert groups are meant to initiate, discuss and solve current issues. This structure ensures that all major stakeholders have a say, while also guaranteeing enough expertise to reach workable solutions. Second, we need to ensure alignment among stakeholders. The actors in the SBR domain form a network, which together provide a service: an information processing chain. Therefore there are frequent meetings (e.g. platform meetings; expert group meetings) to make sure parties know of reported issues and scheduled changes. Regarding adoption by end users, a professional marketing and communications plan is maintained. Third, formal communication procedures must be followed. For example, before releasing a new version of the taxonomy, it must be tested by all stakeholders. Now suppose one party did not perform the test and the release has to be postponed. This needs to be communicated in a uniform way. Table 2 summarizes the compulsory and adaptive measures found in the SBR case study.

Table 2. Summary of compulsory and adaptive measures in the SBR program

\begin{tabular}{|l|l|l|}
\hline Process & Compulsory measure & Adaptive measure \\
\hline Data & $\begin{array}{l}\text { Requesting agencies have to use } \\
\text { BPMN for communicating their } \\
\text { processes with Logius }\end{array}$ & $\begin{array}{l}\text { Requesting agencies are free in } \\
\text { organizing their own internal processes } \\
\text { for handling business reports }\end{array}$ \\
\hline $\begin{array}{l}\text { Use of a single national XBRL } \\
\text { taxonomy with predefined } \\
\text { definitions of data elements }\end{array}$ & $\begin{array}{l}\text { Extensions to the taxonomy are allowed } \\
\text { when the requesting agencies demand } \\
\text { additional information }\end{array}$ \\
\hline Governantructure & $\begin{array}{l}\text { Companies have to connect to } \\
\text { Digipoort (using free coupling } \\
\text { specifications) which is the } \\
\text { exclusive gateway for system to } \\
\text { system reporting in XBRL }\end{array}$ & $\begin{array}{l}\text { Companies are free in deciding which of } \\
\text { their systems will connect to Digipoort } \\
\text { and to what extend XBRL is embedded } \\
\text { in their business transactions (Bolt-on, } \\
\text { build in or embedded) }\end{array}$ \\
\hline $\begin{array}{l}\text { Fixed release schedule for the } \\
\text { taxonomy and Digipoort } \\
\text { components (e.g., certificates) }\end{array}$ & $\begin{array}{l}\text { Flexible requirements and maturity } \\
\text { levels for the consecutive versions }\end{array}$ \\
\hline
\end{tabular}

As outlined in Table 2, the PPC included both compulsory and adaptive measures related to the data, processes, technology and governance aspects of SBR. Both type of measures were required for different purposes. One the one hand, the compulsory measures were needed to mobilize the stakeholders set the standards for SBR. On the other hand, adaptive measures were needed to cater in the heterogeneous stakeholder requirements and maintain their commitment to the SBR program. The combination of measures listed in Table 2 is specific for the SBR case. Section 4 proceeds with a discussion on what types of combinations can be abstracted from the case study.

\section{Discussion}

SBR is a PPC based lean government initiative seeking to reduce the administrative burden for companies and the compliance-monitoring burden for government agencies. The SBR case study illustrates a combination of elements from an 
engineering approach and a learning approach. In the short term, the form of PPC in the SBR case can be characterized as an engineering approach with top-down steering and extensive planning. These elements were necessary in order to mobilize the stakeholders. Varieties of compulsory measures support this engineering approach. Process and data standards are made compulsory, so there seems no room for experimenting. Time is found an important constraint managed by strict deadlines, so no room seems to exist for lessons learned after the deadlines. The technical infrastructure allows for just a single gateway, so there seems no room for redundancy. And yet, on the long run, some elements of the learning approach such as cooperation and bottom up steering were also apparent. These elements were necessary in order to maintain the commitment to the standards (i.e., data, processes and technology) selected by the stakeholders. The learning approach was combined with the engineering approach in at least three ways:

1. Engineering the broad picture, leeway in the details. The simplest combination is engineering the framework, while providing room to maneuver in managing the details. This is highly visible in the compulsory use of the national XBRL- taxonomy, and the possibility for the use of different extensions at the same time. This provides flexibility and learning possibilities for users, while still using (and accounting for) one standard.

2. Implementing a flexible design by an engineering approach. Leeway can also be apparent in the design itself. The more flexible the design, the more room there is for actors to cope with it, the more legitimate an engineering approach may be. An example is the choice for the relatively flexible 'store once report many' design. A one-stop-shop design would demand a lot more change from a lot more actors. In that case a pure engineering approach would be likely to fail, while for a flexible design more elements of this approach are likely to be accepted.

3. Leeway within restrictive procedural rules about decision making. A version of 'command and control by providing leeway' is the top down implementation of decision making procedures. Although the outcomes of the decisions remain open, the procedures (terms, participation) are well defined, so that participants have little room later to reject the decisions on the ground that they had no influence on the outcome. Examples are procedures for agencies to provide existing process models in non-standard formats. Another example is the governance model, in which collective go-no go moments are required in a strict time frame. These combinations provide possibilities for learning by doing within an engineering frame.

The case suggests that a combination between the approaches has been found, by using an engineering approach and providing leeway at the same time. As suggested by theory, this 'management by paradox' could very well be an important success factor of the SBR-case. While there is no set of hard or quantifiable metrics for evaluating the success of this methodology, the prospect of the nationwide requirement to deliver official reports in the XBRL format indicates that the stakeholders have made significant progress in establishing the necessary infrastructure for SBR. In the case of SBR, the combination of such compulsory and adaptive measures has proven to be able to sustain progression in achieving the minimally required program milestones. Considering the results of the SBR program, the Dutch Government has announced that Digipoort will be the exclusive channel for exchanging financial reports with government agencies starting 2013. 


\section{Conclusions and Further Research}

Managing public-private collaboration projects is a difficult process, subject to different interests, heterogeneous processes and changing political priorities. Since public and private agencies often have various interests, measures are needed to mobilize their resources on the short run and to sustain their commitment on the long term. Finding this balance is a delicate process. This paper illustrates the need for, and the use of, an adaptive program management methodology, which includes both compulsory and adaptive elements. As such, the case study shows that both compulsory and adaptive measure are necessary as command and control is needed to deliver milestones and standards, while maneuvering space or leeway is needed to mobilize stakeholders and profit from learning effects. In this way, program managers plan for and continue with the most crystalized project outcomes, while at the same time plan for a higher maturity level in future releases.

One of the questions rising from this research is under which conditions a combination of compulsory and adaptive measures would succeed. In retrospect, the case study has four specific conditions that need to be highlighted, since they provide a basis for PPC. Firstly, there is a sufficient level of political consensus on the need for SBR in the Netherlands. Secondly, the technology and data representation standards used (XBRL) and the infrastructure needed (government gateway) are based on accepted open standards and use proven building blocks. Thirdly, the introduction of SBR does not demand any immediate changes in the current laws on business-to-government reporting. This is highlighted by the slogan 'store once, report to many'. We argue that when legal changes would have been required, the implementation would have progressed slower. Finally, an important condition in the SBR case is that it entails a clear business case for the participating stakeholders. Further research may consider other cases in which these conditions are not in place. Careful evaluation of the conditions for success and sustainability is required on a case-by-case basis in order to assess the costs and benefits and the likelihood of success of such an approach. Such cases would allow further specification and testing the type of compulsory and adaptive measures needed for public sector reengineering.

\section{References}

1. Osborne, S.: Public-private partnerships: theory and practice in international perspective. Taylor and Francis, London (2000)

2. Donahue, J.D., Zeckhauser, R.J.: Public-Private Collaboration. In: Moran, M., Rein, M., Goodin, R.E. (eds.) The Oxford Handbook of Public Policy. Oxford University Press, Oxford (2006)

3. Tan, Y.H., Bjørn-Andersen, N., Klein, S., Rukanova, B. (eds.): Accelerating Global Supply Chains with IT-Innovation. Springer, Berlin (2011)

4. Kerschbaumer, K.: Public-private partnerships in Eastern Europe: Case studies from Lithuania, Republika Srpska and Albania. Eurohealth 13, 7-9 (2007)

5. Reijniers, J.J.: Organization of public-private partnership projects: The timely prevention of pitfalls. International Journal of Project Management 12, 137-142 (1994) 
6. van Veenstra, A.F., Janssen, M., Tan, Y.-H.: Towards an understanding of E-government induced change - drawing on organization and structuration theories. In: Wimmer, M.A., Chappelet, J.-L., Janssen, M., Scholl, H.J. (eds.) EGOV 2010. LNCS, vol. 6228, pp. 1-12. Springer, Heidelberg (2010)

7. de Bruijn, J.A., ten Heuvelhof, E.F., Veld, R.J.: Process Management. Why Project Management Fails in Complex Decision Making Processes. Kluwer Academic Publishers, Dordrecht (2002)

8. Kling, R., Lamb, R.: IT and Organizational Change in Digital Economies: A Sociotechnical Approach. In: Brynjolfsson, E., Kahin, B. (eds.) Understanding the Digital Economy. Data, Tools, and Research. The MIT Press, Cambridge (2000)

9. Kwak, Y.: A Brief History of Project Management. In: Carayannis, E.G., Kwak, Y., Anbari, F.T. (eds.) The Story Of Managing Projects: An Interdisciplinary Approach, pp. 19. Praeger Publishers, Westport (2005)

10. Hammer, M., Champy, J.: Reengineering the Corporation: A Manifesto for Business Revolution. Harper Business (1993)

11. Lundin, R., Söderholm, A.: A Theory of The Temporary Organization. Scandinavian Journal of Management 11, 437-455 (1995)

12. von Stamm, B.: Managing Innovation, Design and Creativity. John Wiley and Sons Ltd., Chichester (2003)

13. Dempsey, P.S., Goetz, A.R., Szyliowicz, J.S.: Denver International Airport: lessons learned. McGraw-Hill, New York (1997)

14. Loureiro, G., Curran, R.: Complex Systems Concurrent Engineering; Collaboration, Technology Innovation and Sustainability. Springer, London (2007)

15. Koppenjan, J.F.M., Klijn, E.H.: Managing Uncertainties in Networks. Routlegdge, London (2004)

16. Morris, P.W.G., Hough, G.H.: The Anatomy of Major Projects: A Study of Project Management. John Wiley \& Sons, Chichester (1987)

17. Geraldi, J.G.: The balance between order and chaos in multi-project firms: A conceptual model. International Journal of Project Management 26, 348-356 (2008)

18. Bharosa, N., Janssen, M., Hulstijn, J., Van Wijk, R., De Winne, N.: Principles for launching Standard Business Reporting: Lessons learned from the Netherlands. DgO. ACM, Maryland (2011)

19. Debreceny, R., Felden, C., Ochocki, B., Piechocki, M.: XBRL for Interactive Data: Engineering the Information Value Chain. Springer, Berlin (2009)

20. Wimmer, M.A.: Integrated Service Modelling for Online One-stop Government. Electronic Markets 12, 149-156 (2003)

21. White, S., Miers, D.: BPMN Modeling and Reference Guide. Future Strategies Inc. Lighthouse Pt, FL (2008) 